\title{
Advice to consume 1-2 portions of oily fish per week improves vitamin D status
}

\author{
C. M. Fisk ${ }^{1}$, D. P. Reidlinger and T. A. B. Sanders ${ }^{1}$ on behalf of the CRESSIDA study group \\ ${ }^{1}$ Division of Diabetes and Nutritional Sciences, King's College London, Franklin-Wilkins Building 150 Stamford Street, \\ London, SE1 $9 \mathrm{NH}$, UK
}

Dietary sources of vitamin D may only play a minor role in meeting vitamin D requirements compared with ultraviolet exposure ${ }^{(1)}$. Data from the National Diet and Nutrition Survey suggest that vitamin D insufficiency, defined as serum 25-hydroxyvitamin D $(25(\mathrm{OH}) \mathrm{D})<25 \mathrm{nmol} / \mathrm{L}$, is widespread in the $\mathrm{UK}^{(2)}$. Except for oily fish, there are few rich dietary sources of vitamin D. Furthermore, high intakes of unrefined cereals can contribute to low serum $25(\mathrm{OH}) \mathrm{D}$ concentrations by increasing the catabolism of vitamin $\mathrm{D}$ which is thought to be due to their high phytic acid content interfering with calcium absorption ${ }^{(3)}$. We report the association between dietary vitamin D intake and $25(\mathrm{OH}) \mathrm{D}$ at baseline in subjects recruited into a randomised controlled trial, and the changes in vitamin $\mathrm{D}$ intake and $25(\mathrm{OH}) \mathrm{D}$ following randomisation to two dietary interventions.

The CRESSIDA trial (ISRCTN92382106) randomised 165 healthy non-smoking men and women aged 40-70 y to a cardioprotective (CP) or a control (C) diet for 12 wks. Blood samples and 4-d diet records completed at baseline and follow-up were available for analysis in 162 subjects. The cardioprotective diet included salt $<6 \mathrm{~g} / \mathrm{d}$, saturated fatty acids $<10 \%$ of food energy, oily fish intake 1-2 portions/wk and fruit and vegetables 5 portions/d, and supplied at least half of the cereal intake from wholegrains. The control diet was a typical well balanced British diet but contained oily fish less than once a month. All subjects abstained from dietary supplements throughout the study. Table 1 shows vitamin D intakes and plasma concentrations of $25(\mathrm{OH}) \mathrm{D}$ determined by immunoassay.

\begin{tabular}{|c|c|c|c|c|c|c|c|c|}
\hline & \multicolumn{4}{|c|}{ Vitamin D intake $(\mu \mathrm{g} / \mathrm{d})$} & \multicolumn{4}{|c|}{$25(\mathrm{OH}) \mathrm{D}(\mathrm{nmol} / \mathrm{L})$} \\
\hline & \multicolumn{2}{|c|}{$\mathbf{C P}(n=80)$} & \multicolumn{2}{|c|}{$\mathbf{C}(n=82)$} & \multicolumn{2}{|c|}{$\mathbf{C P}(n=80)$} & \multicolumn{2}{|c|}{$\mathbf{C}(n=82)$} \\
\hline & Mean & $\overline{\mathrm{SD}}$ & Mean & $\overline{\mathrm{SD}}$ & Mean & $\mathrm{SD}$ & Mean & $\overline{S D}$ \\
\hline Baseline & 3.0 & 2.5 & 2.9 & 2.3 & 58.0 & 18.7 & 60.3 & 22.8 \\
\hline Follow-up & $6.6^{*}$ & 4.3 & 2.7 & 1.4 & $68.4 *$ & 23.0 & 58.4 & 19.9 \\
\hline
\end{tabular}

$* P<0.001$ compared to control group.

Dietary vitamin D intake and $25(\mathrm{OH}) \mathrm{D}$ concentrations were correlated at baseline $(r=0.277 ; P<0.001)$. Vitamin D intake increased following the cardioprotective diet compared with the control as a consequence of the increased consumption of oily fish. Serum $25(\mathrm{OH}) \mathrm{D}$ concentrations at 12 weeks were $9.2 \mathrm{nmol} / \mathrm{L}(P<0.001)$ greater in the $\mathbf{C P}$ diet group compared to the $\mathbf{C}$ group when adjusted for baseline $25(\mathrm{OH}) \mathrm{D}$, age, BMI, gender, ethnicity and seasonality. This increase is similar to the increase in $25(\mathrm{OH}) \mathrm{D}$ found after supplementation with $5 \mu \mathrm{g}$ vitamin D3 per day for 4 weeks in the winter months ${ }^{(4)}$. In conclusion, the consumption of oily fish $1-2$ times a week improves vitamin D status, and the inclusion of wholegrain cereals (mainly breakfast cereals and bread) as part of a cardioprotective diet does not have an adverse effect on vitamin D status.

This work was supported by the Food Standards Agency and Department of Health.

1. Norman A, Bouillon R, Whiting S et al. (2007) J Steroid Biochem Mol Biol. 103, 204-205.

2. Bates B, Lennox A, Prentice A et al. (editors) (2012) Department of Health. 1-79.

3. Dagnelie PC, Vergote F, van Staveren WA et al. (1990) Am. J. Clin. Nutr. 51, $202-208$.

4. Fisk CM, Theobald HE \& Sanders TAB (2012) J Nutr 142, 1286-1290. 